\title{
Properties of Polyetheretherketone (PEEK) transferred materials in a PEEK-steel contact
}

\author{
Debashis Puhan ${ }^{1}$ and Janet S. S. Wong ${ }^{1^{*}}$
}

${ }^{1}$ The Tribology Group, Department of Mechanical Engineering, Imperial College

London, Exhibition Road, London, United Kingdom SW7 2AZ

*Corresponding author: j.wong@imperial.ac.uk

\begin{abstract}
Polyetheretherketone (PEEK) is a high performance polymer that can be an alternative to metal for some moving components in unlubricated conditions. During rubbing, PEEK is transferred to the counterface. The formation and properties of PEEK transfer films on steel and sapphire are studied by in-situ observations of PEEK wear process, contact temperatures and triboemission, as well as FTIR and Raman spectroscopies ex situ. Our results suggest that frictional heating alone may not be sufficient to generate PEEK degradation observed in the transfer materials. Triboplasma observed during rubbing, together with the mechanical shear, may promote generations of radicals and degradation of PEEK, which subsequently influence the properties of PEEK transfer film and performance of polymer-metal tribopair.
\end{abstract}

\section{Introduction}

Polyetheretherketone (PEEK, see Figure 1), a member of the polyaryletherketone family, is a high performance polymer (HPP) widely used in applications involving relative motion. Its good chemical resistance, high strength and high wear resistance make it an ideal material for tribological applications [1,2] and hence has been used as alternatives to various metallic components such as seal rings, transmission gears, bushings, sliders, bearings and valves. In these applications, it is common that PEEK is rubbed against a metal counterface. The properties of the PEEK-metal interface thus govern the tribological performance of PEEKmetal tribopairs, including contact temperature, friction and wear [3-5].

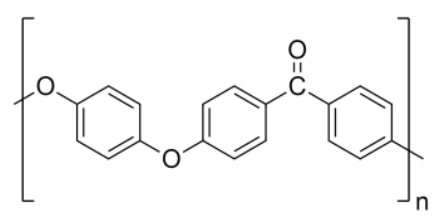

Figure 1: Chemical structure of Polyetheretherketone (PEEK)

A polymeric transfer film may form on the counterface when a polymer is rubbed against metal. It can be formed by physical forces such as adhesion or by chemical reactions $[6,7]$. PEEK films have been described as continuous, uniform, and thick [8]. Yet, there is no standard definition of a good transfer film. Usually a smooth and continuous transfer film is 
considered beneficial for protecting the polymer surface from the hard-metallic asperities, reducing wear. The material transfer process and properties of transferred materials are thus crucial for the development of better materials with increased durability and lower friction. However in-depth understanding of this process is lacking. Only qualitative and often subjective descriptions are made. Hence, determining the correlations among transfer film properties, friction and wear have been challenging.

The formation of PEEK polymeric transfer films on metallic counterfaces has been attributed to its adhesion properties [9]. Few studies have characterised these films in details. Laux et al. [8], using a pin-on-disc geometry, concluded that the mean transfer film thickness and the amount of PEEK wear were not correlated. In addition, the transfer film was the thickest when the sliding motion was perpendicular to the counterface roughness direction. The wear rates increase with increasing contact pressure. Zhang et al. conducted a FTIR analysis of worn PEEK surfaces and suggested changes in chemical bonding and crosslinking improved the adhesion of plasma treated PEEK to steel countersurface [10]. The steel surface however was not characterised.

Properties and the formation of transfer films are commonly believed to be contact temperature driven. Other factors, including triboemission, may also play a role. It has been found that plasma can cause polymer degradation [11] and affect friction and wear [12]. The aim of this paper is to examine factors that contribute to the properties of PEEK transfer films in a PEEK-steel contact in non-lubricated conditions. This understanding is achieved by observing in-situ PEEK materials transfer process to counterfaces. A rotating PEEK disc was rubbed against a stationary steel or sapphire ball. Chemical and topological analysis were conducted on transferred materials. Results are correlated with contact temperature and plasma (UV emission) generated during rubbing.

\section{Materials and Methodologies}

\subsection{Materials system}

A grade of commercially available Victrex PEEK was cut from an injection moulded sheet stock of $10 \mathrm{~mm}$ thickness. Its glass transition temperature $\left(\mathrm{T}_{\mathrm{g}}\right)$ and a melting temperature $\left(\mathrm{T}_{\mathrm{m}}\right)$ are $143^{\circ} \mathrm{C}$ and $343^{\circ} \mathrm{C}$ respectively. The crystallinity of the sample, determined using differential scanning calorimetry, was less than 30\%. The $6 \mathrm{~mm}$ diameter steel balls (AISI52100) were purchased from PCS Instruments Ltd and sapphire hemispheres of $5 \mathrm{~mm}$ diameter were purchased from Swiss Jewel, USA. The roughness of the disc (Ra) was 1-1.2 $\mu \mathrm{m}$ while that of the balls were less than $0.02 \mu \mathrm{m}$. The material properties of the balls and discs are listed in Table 1. 
Table 1: Properties of the ball and disc material

\begin{tabular}{cccc}
\hline Properties & $\begin{array}{c}\text { PEEK Disc } \\
{[13]}\end{array}$ & $\begin{array}{c}\text { Sapphire } \\
\text { Ball [14] }\end{array}$ & Steel Ball \\
\hline \hline Density kg/m³ & 1320 & 3980 & 7700 \\
Thermal Conductivity W/m-K & 0.29 & 46 & $21[15]$ \\
Thermal Diffusivity m²/s & $1.47 \times 10^{-7}$ & $1.51 \times 10^{-6}$ & $1.29 \times 10^{-5}$ \\
Specific heat J/kg-K & 1340 & 7610 & 461 \\
\hline
\end{tabular}

New disc and ball specimens were used for each test and no lubricant was used. Prior to tests, steel and sapphire balls were cleaned with toluene (analytical reagent grade, $99.8 \%$, Fischer Chemicals) in an ultrasonic bath and washed with isopropanol (analytical reagent grade, 99.8 $\%$, Fischer Chemicals) while the discs were wiped with lint free wipes soaked in isopropanol. Both ball and disc samples were thoroughly dried using a drier before each test. All solvents were used as received. All test were done at room temperature $\left(22-27^{\circ} \mathrm{C}\right)$ with relative humidity (40-55\%).

\subsection{Friction test}

Coefficient of friction was measured with a CETR UMT tribometer in a ball on disc configuration. A point contact was created by a stationary steel ball loaded against a unidirectional rotating PEEK disc (see Figure 2). Test conditions are listed in Table 2. Average coefficient of friction is reported from the average of three tests. An electrometer (Keithley $6517 \mathrm{~B}$ ) connected to a homebuilt charge sensor (details in [16]) was used to record the charge accumulation on the disc surface. The sensor was placed diametrically opposite to the contact, with its tip positioned $2 \mathrm{~mm}$ above the wear track. 
Table 2: Operating conditions

\begin{tabular}{|c|c|c|}
\hline & PEEK-Sapphiı & PEEK-Steel \\
\hline Ball diameter mm & 5 & 6 \\
\hline Load N & \multicolumn{2}{|c|}{10} \\
\hline Speed m/s & \multicolumn{2}{|c|}{2} \\
\hline Time s & \multicolumn{2}{|c|}{1800} \\
\hline Sliding distance $\mathrm{m}$ & \multicolumn{2}{|c|}{3600} \\
\hline Initial average pressure, $\mathrm{P}_{\text {mean }} \mathrm{GPa}$ & 0.12 & 0.11 \\
\hline Initial maximum pressure, $\mathrm{P}_{\max } \mathrm{GPa}$ & 0.18 & 0.16 \\
\hline Semi contact width (a) $\mathrm{m}$ & $0.16 \times 10^{-3}$ & $0.17 \times 10^{-3}$ \\
\hline
\end{tabular}

A K type thermocouple was attached to the side of the ball with high temperature superglue to monitor the temperature of the ball. RS Pro 1384 Data Logger recorded the temperature at 1 $\mathrm{Hz}$ during the test. The disc surface temperature was measured using an Omega IR-USB infrared sensor, suitable for non-contact temperature monitoring of polymers. The temperature was recorded at $1 \mathrm{~Hz}$ by a PC using a dedicated software.

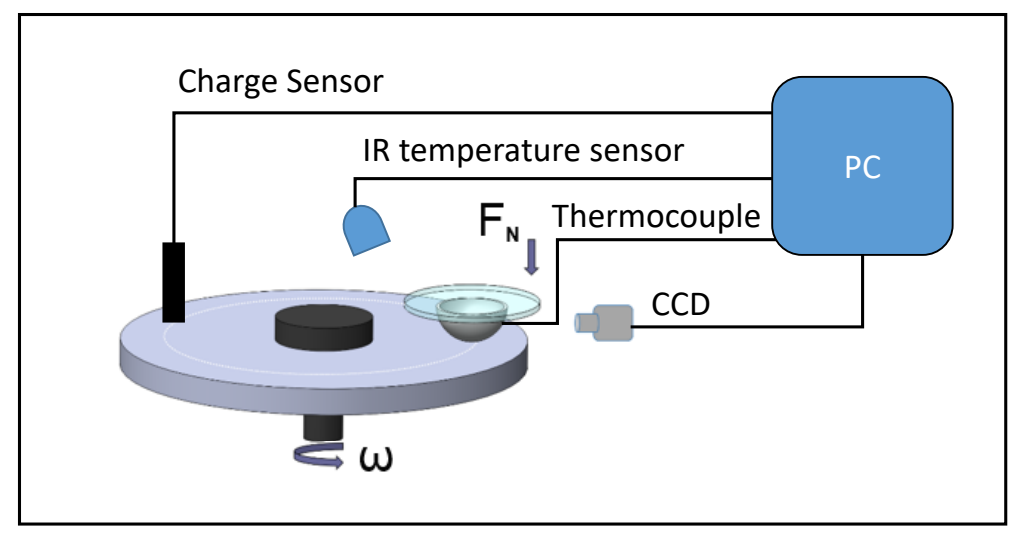

Figure 2: Schematic of the friction test experimental setup.

\subsection{In situ IR thermography}

Infrared IR thermography was used to obtain temperature of a PEEK-sapphire contact in situ [17]. A FLIR X6540 SC camera, with a high resolution $640 \times 512$ pixel detector sensitive to IR wavelengths from 3 to $5 \mu \mathrm{m}$, was positioned above the stationary sapphire hemisphere. Thermal radiation from the contact was transmitted through the IR transmissive sapphire 
specimen and was collected through a $5 \times$ objective lens. IR images were captured at $4 \mathrm{~Hz}$ for 30 minutes of sliding. Note that the temperature rise at the asperity level cannot be measured since such heat source is very short lived $\left(10^{-3}-10^{-5} \mathrm{~s}\right)$ [18]. Hence only the steady state nominal temperature at the contact is obtained.

The main contribution to the radiation detected by the IR detector are from (1) PEEK disc, (2) sapphire hemisphere, and (3) reflected ambient radiation. In this work, the emissivity of PEEK and sapphire are taken as 0.95 [19] and 0.45 [20] respectively, while the contributions from secondary reflection and reflected radiation were neglected as in ref [21]. Having said that, the contact temperature obtained may be an overestimation. The bulk temperature of the sapphire hemisphere was monitored by a K type contacting thermocouple to ascertain the lower bound of the contact temperature. Note that SI stands for Supplementary Information. Sections, figures and table number starting with 'S' are in the SI-1.

\subsection{Plasma observations}

Based on the setup shown in Figure 2, the PEEK-steel sliding contact was viewed from the side to observe the plasma generated using a UV sensitive camera (Hamamatsu ImagEM X2) Images were captured with a $5^{\times}$objective (Mitotoyo) at 8 frames/ second under no background light conditions.

The optical spectrum of the generated plasma was obtained using a spectrometer (Ocean Optics QE Pro) coupled with a fibre optic through a stationary sapphire hemisphere when it was rubbed against a rotating PEEK disc.

\subsection{Surface Analysis using SEM-EDS, FTIR and Raman}

Optical images were captured using a HIROX RH 2000 microscope. SEM images were taken with a Hitachi S3400 instrument in secondary electron mode and back scattered electron mode at $20 \mathrm{kV}$. The energy dispersive X-ray (EDX) mode on the SEM was used for elemental analysis of the test samples.

FTIR and Raman spectroscopies were used to characterise PEEK transferred materials on counterfaces. Information of peak assignments for FTIR and Raman spectra can be found in section S-1. A Fourier transform infrared (FTIR) Spectrometer (Spectrum 100, Perkin Elmer, USA) was used to collect IR spectra. Each spectrum consists of 100 scans performed between $700 \mathrm{~cm}^{-1}$ and $3600 \mathrm{~cm}^{-1}$ at a wavenumber resolution of $4 \mathrm{~cm}^{-1}$. IR spectra collected were distorted due to the low reflectance of PEEK disc. Kramers-Kronig conversion was applied to obtain corrected absorption spectra. 
A HORIBA Labram HR Evolution Raman spectroscope, with a $785 \mathrm{~nm}$ laser, was used to collect Raman spectra. To avoid sample degradation by laser heating, the laser power was kept as low as possible. Results were obtained from 20 scans of $1 \mathrm{~s}$ each between $700 \mathrm{~cm}^{-1}$ and 1800 $\mathrm{cm}^{-1}$ using a $20 \times$ objective.

\section{Results and Discussions}

\subsection{Summary of friction test results}

Fluctuations in frictional forces, and hence friction coefficient, is observed during friction tests (Figure 3). Friction coefficient of the PEEK-steel contact show larger variation than that of the PEEK-sapphire contact. Since friction tests were conducted in unlubricated conditions, this level of variations among tests are common and deemed acceptable. Average steady state friction coefficients of the PEEK-steel and PEEK-sapphire contacts are around $0.26 \pm 0.05$ and $0.17 \pm 0.01$ respectively.

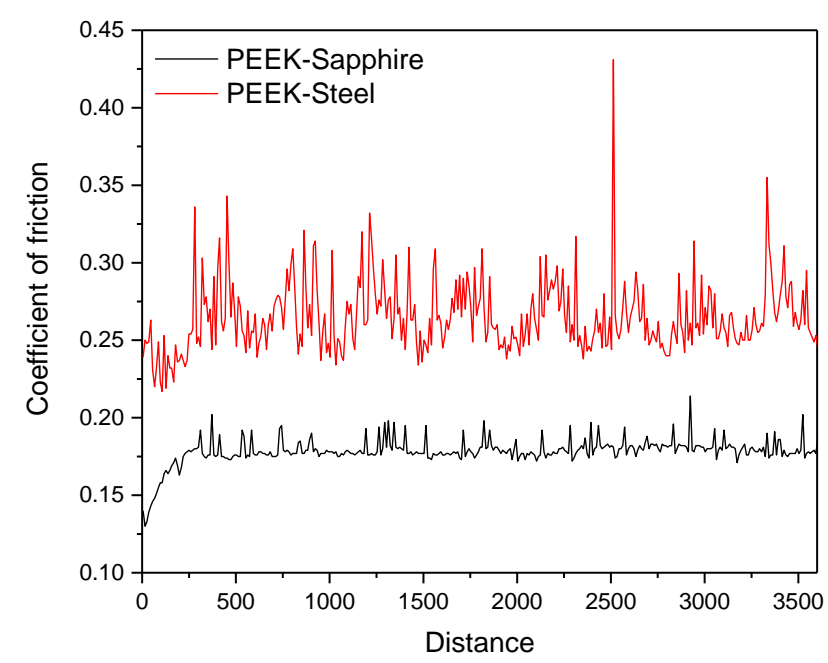

Figure 3: Coefficient of friction of PEEK-steel and PEEK-sapphire contacts recorded during rubbing.

After friction tests, rubbing surfaces were examined. While more debris are found with the PEEK-steel contact (Figure 4a), features on rubbed steel and sapphire surfaces are similar. Loose debris, including thick accumulations at the inlet and outlet of the contact (labelled as sheared film, see Figure $4 \mathrm{~b}$ and $4 \mathrm{~d}$ ), can be removed easily by wiping the surface with cleaning tissue paper. Even more debris are removed after sonication in acetone (compare Figures $4 \mathrm{~b}$ vs. $4 \mathrm{c}$ and Figures $4 \mathrm{~d}$ vs. 4e), after which strongly adhered PEEK transferred materials is exposed. Transfer layers on wear scars are heterogeneous and consist of two distinct regions: patches with a thickness of about 2-4 $\mu \mathrm{m}$, referred as transfer films; and rainbow coloured 
regions which are very thin films (about 20-200 nm, see Figure $4 \mathrm{~b}$ and $4 \mathrm{c}$ for definitions). Elongated patches along the sliding direction are termed as streaks.
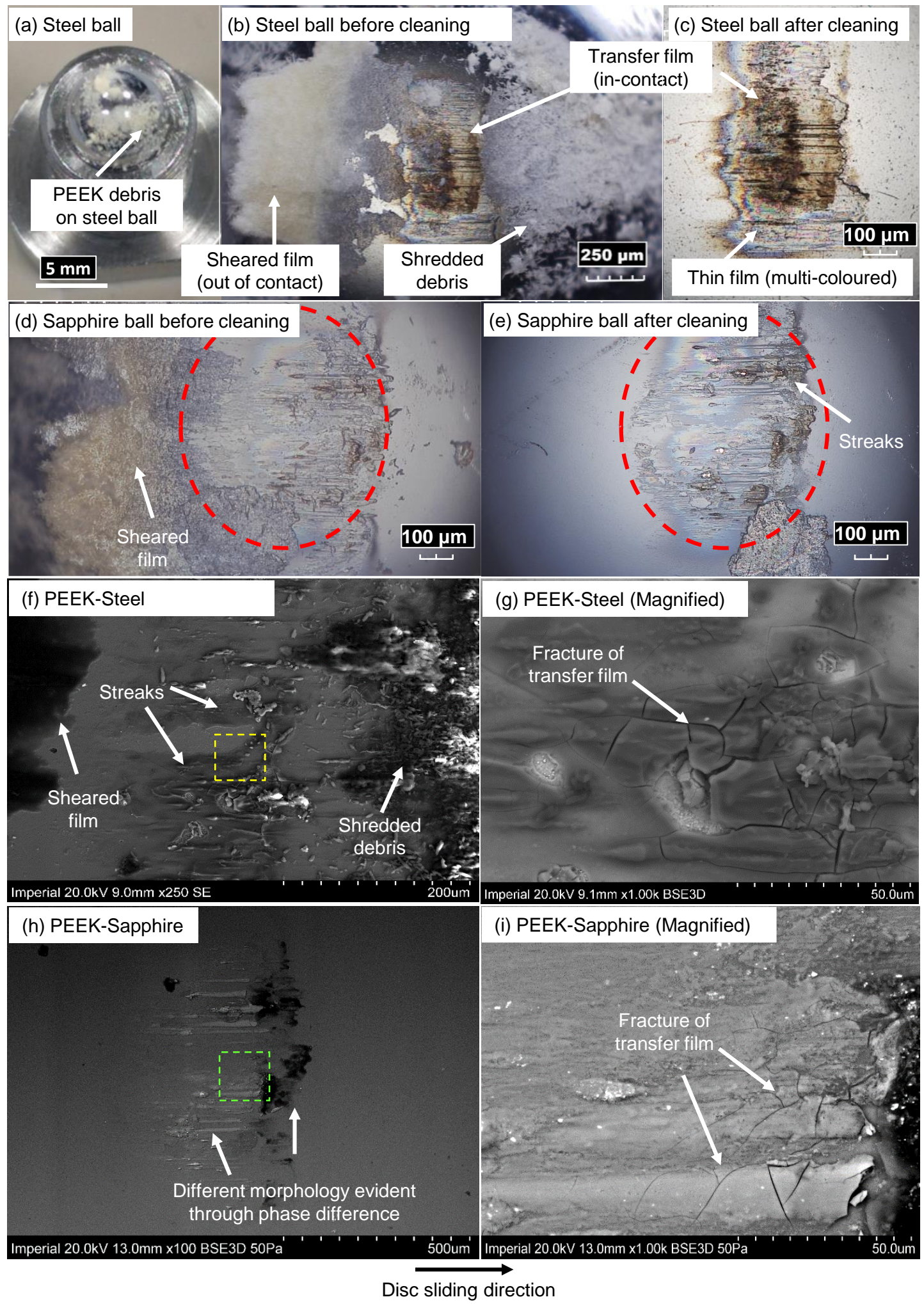

Figure 4:(a) PEEK debris (appeared white) on a steel ball after friction test; (b) PEEK transferred materials on a steel ball right after the test; (c) PEEK transfer film on a steel ball 
after cleaning; (d) PEEK transferred materials on a sapphire ball right after the test; (e) PEEK transferred materials on a sapphire ball after cleaning; (f) SEM image of PEEK transferred materials on a steel ball right after the test; (g) Magnified view showing cracks in the square region on image (f) in back scattered electron mode (BSE); (h) Back scattered electron scanning micrograph of PEEK transferred materials on a sapphire ball right after the test; (i) Magnified view showing cracks and fracture in the square region on image $(\mathrm{h})$. Cleaning refers to wiping and sonication in acetone.

The strongly adhered materials in wear scars were examined with backscattered SEM electron images (Figure $4 \mathrm{~g}-4 \mathrm{i}$ ). Heavy and light atoms appear brighter and darker respectively in these images. The darker regions are polymeric, consisting of carbon and oxygen, while both counterface materials and PEEK-based materials are detected in the lighter-colored streaks (see Table S2-1, Figure S2-1; and Table S2-2, Figure S2-2 for EDX results from sapphire and steel wear scars respectively). Micro-cracks are observed on the thin streaks, suggesting that they are brittle (see Figure $4 \mathrm{~g}$ and $4 \mathrm{i}$ ). The cracks may form due to repetitive loading [22]. These may also be associated with the deformation of the polymer below its $\mathrm{T}_{\mathrm{g}}$ or a change in flexibility of polymer chains arising from chain scission [23] or UV irradiation [24].
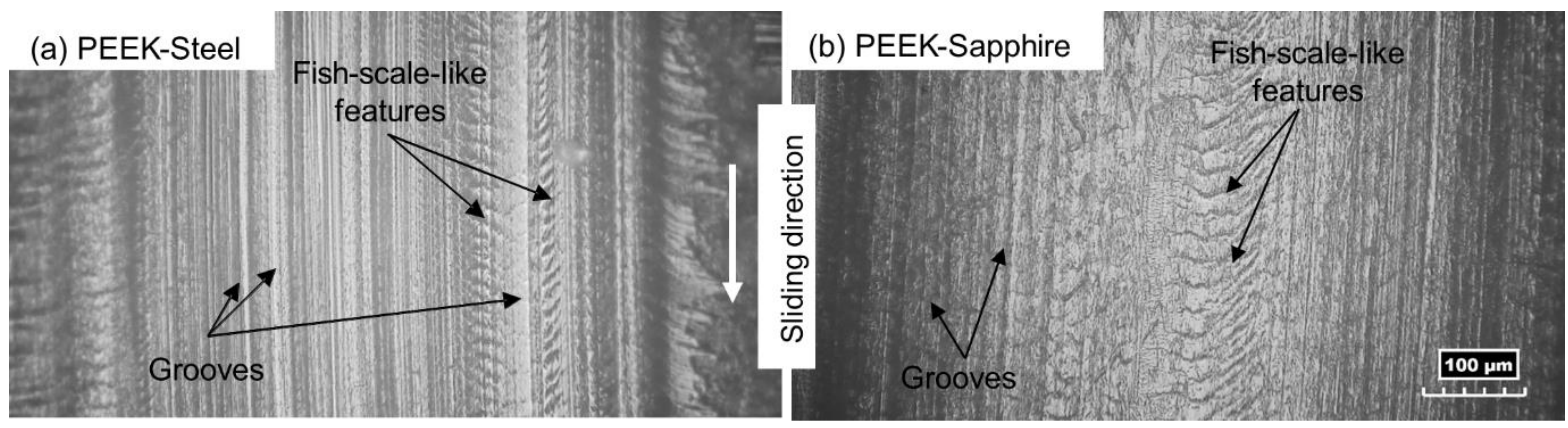

Figure 5: Wear tracks on PEEK discs formed by (a) PEEK-steel and (b) PEEK-sapphire contacts.

Wear tracks on PEEK discs formed by PEEK-sapphire and PEEK-steel contacts are shown in Figure 5. They show grooves, and fish-scale-like features. Grooves occur when hard asperities of the ball surface plough through the softer polymer. It is more severe in the PEEK-steel contact. Fish-scale-like patterns could be formed due to tensile drawing followed by compressive ironing of the polymer surface [25] in the presence of flowing and non-flowing regions of the polymer, giving rise to stick-slip motion [26]. The parabolic folds or ridges suggests that the temperature may have been below the $\mathrm{T}_{\mathrm{g}}[10]$. These results suggest in these contacts both abrasive and adhesive wear occurred.

Factors that govern polymer wear processes include materials properties, test conditions and contact conditions. The similarity of the wear scar and wear tracks obtained from PEEKsapphire and PEEK-steel contacts is likely due to the severity of the chosen test condition. As a result, PEEK in both contacts undergoes similar deformation and degradation. This allows us to apply results obtained from in-situ wear and contact temperature measurements from a 
PEEK-sapphire contact, presented in sections 3.2.1 and 3.3.1 respectively, to a PEEK-steel contact.

\subsection{PEEK wear process}

\subsubsection{In-situ wear observations}

A PEEK-sapphire contact was monitored in-situ through the sapphire during rubbing. This allowed the PEEK wear process to be observed in real-time (video SI 2). Snapshots of in-situ wear process in PEEK-sapphire contacts (Figure 6) show that debris are formed by two processes (i) primary debris are formed by the detachment of the ploughed out or deformed materials; and (ii) secondary debris formed by shredding (tearing) or shearing of the primary debris.
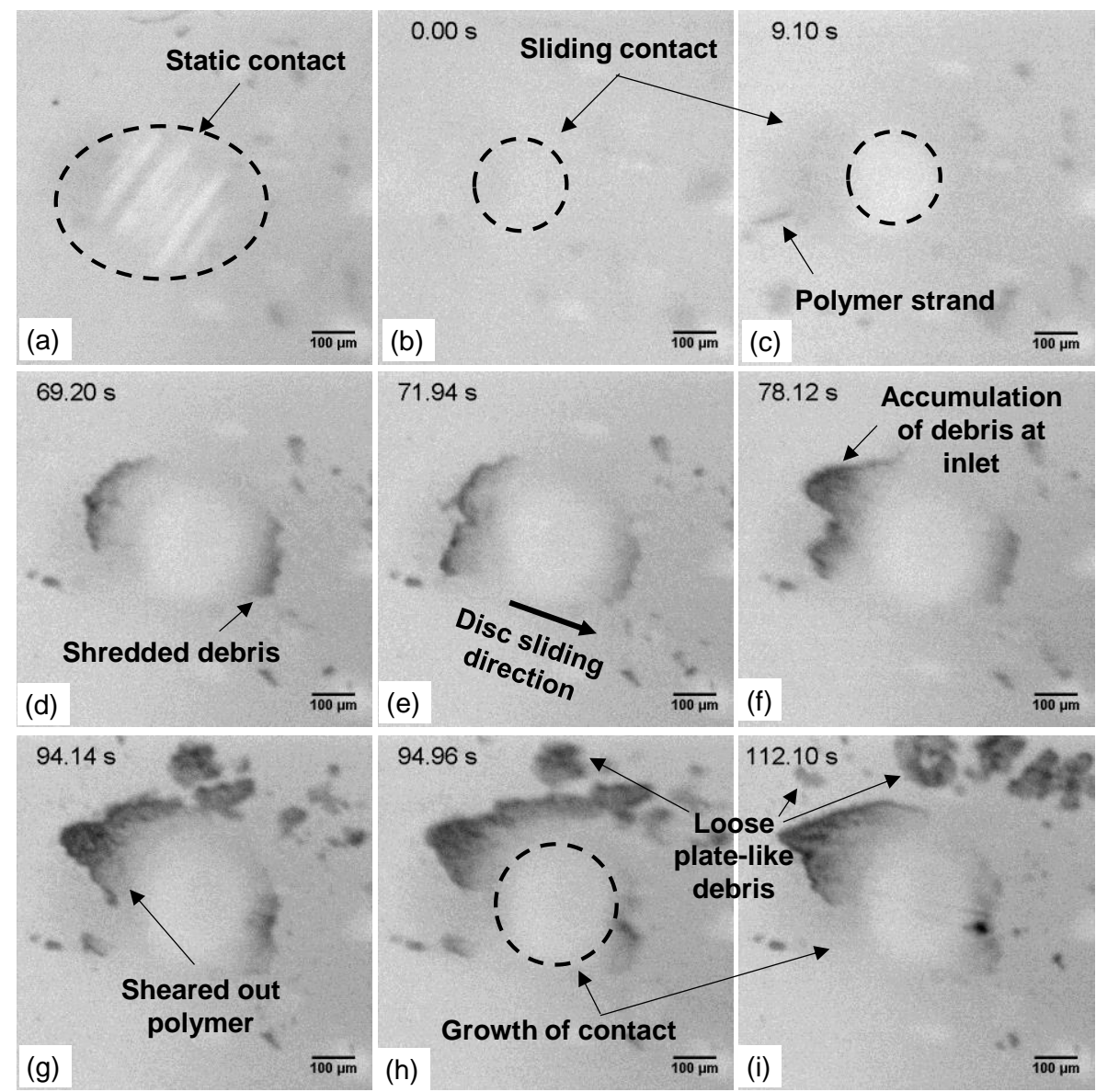

Figure 6: Snapshots of a PEEK-sapphire contact imaging at $50 \mathrm{~Hz}$, showing the wear process of PEEK in situ.

During rubbing, long strands and plate like debris are formed. Long strands (see Figure 6c) are more common at the beginning of sliding when sharp asperities of the countersurface plough through the soft polymer surface, resulting in groves on the polymer surface. As sliding continues, these asperities become blunt either by fracture due to the shear stress acting on 
them or are covered with the softer transferred materials. Thermal effects and fatigue may also become more prominent and polymer is removed by a combination of ploughing and microcutting. The resulting plastic flow may give rise to plate-like debris as shown in Figure $6 \mathrm{~d}-6 \mathrm{f}$.

As a result of repeated cyclic loading, the deformed, ploughed out polymer may be removed from the contact and the wear track, forming loose debris (see Figure $6 \mathrm{~h}-6 \mathrm{i}$ ). They may accumulate at the inlet (Figure 6f). Some of them re-enter the contact and may be shredded into smaller pieces (Figure $6 \mathrm{~d}, 6 \mathrm{~g}$ ). They may re-adhere to the polymer surface or become trapped between asperities of the counterface by compression [6,27], forming strongly adhered thin film or transfer film.

\subsubsection{Analysis based on FTIR spectra}

FTIR spectra of PEEK transferred materials on steel balls, PEEK wear track and pristine PEEK disc are shown in Figure 7. Important observations are summarized in Table 3. Details of the IR spectra can be found in Figure S3-1 and Table S3-1.

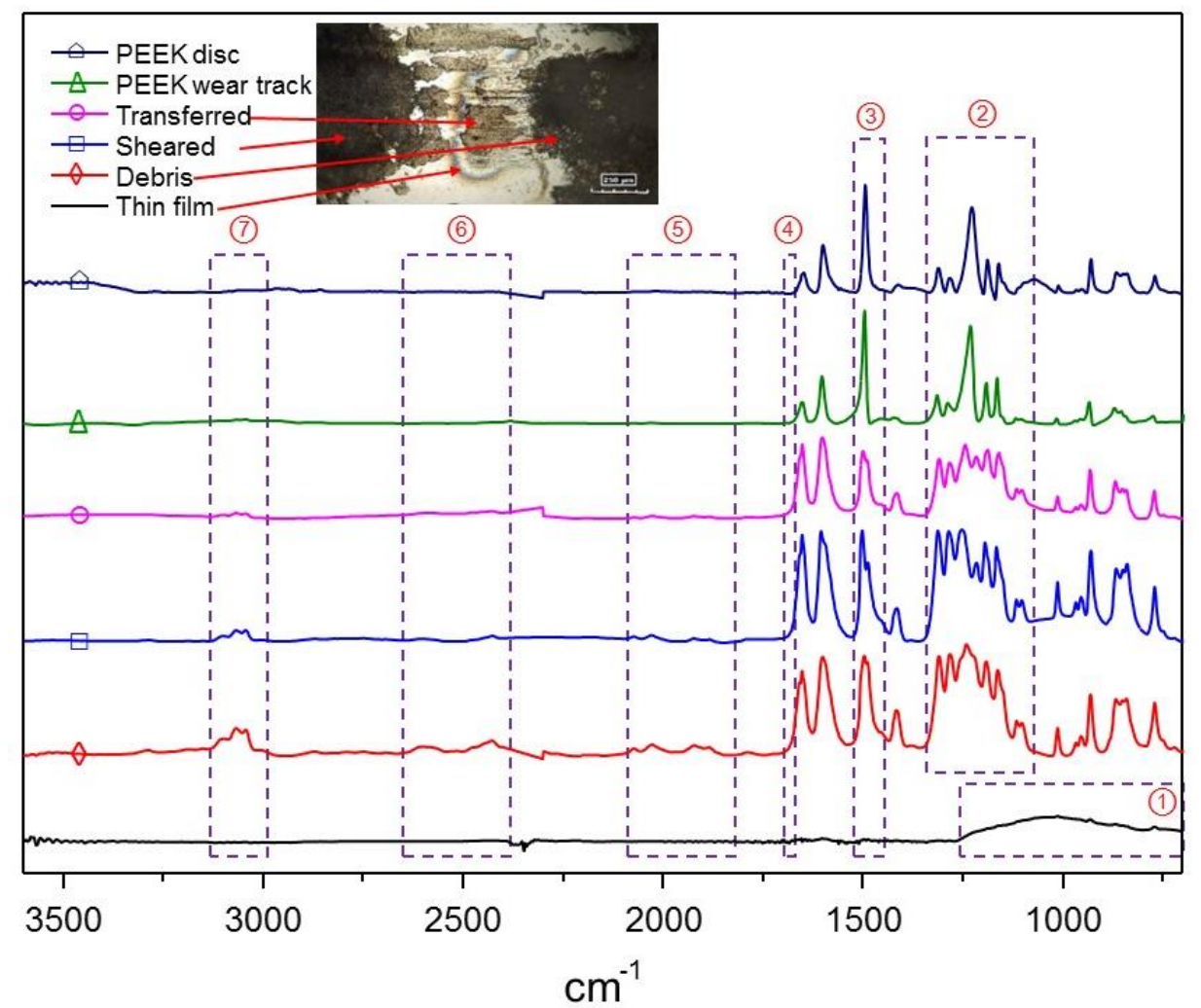

Figure 7: FTIR spectra of pristine PEEK disc, PEEK wear track and various PEEK transferred materials on steel.

To facilitate discussion, seven zones are highlighted in Figure 7. The spectrum of thin rainbow coloured film on steel ball wear scar (black line, no symbol) is mostly featureless, with a broad peak between 1200 and $700 \mathrm{~cm}^{-1}$ (zone 1). This suggests that the ketone and ether groups present on the PEEK chain have been severely oxidized and the remains are mainly 
amorphous carbonaceous material. The low thickness (in sub-micron range) of thin films may make their identification difficult by FTIR in reflection mode.

Changes in FTIR spectra from transferred materials, other than thin films, show peak shifts compared to that of pristine PEEK, and hence suggest that rubbing promotes chemical changes of PEEK (see zone 2 - 4). The relative intensities and shoulders of many peaks are altered, suggesting that the transfer films, sheared films and debris underwent some degree of degradation such as oxidation, crosslinking, changes in molecular orientation and substitution, as summarised in Table 3 (see also Section S-4).

The FTIR spectrum of the PEEK wear track (green triangle) have bands that are narrower and shift towards slightly higher frequencies as compared to pristine PEEK (navy pentagon), which suggests a slight increase in crystallinity on the wear track.

In case of PEEK transferred materials, the bands are broader, and new peaks and shoulders appear. Generally, the bands related to carbonyl stretching and ring vibration (zone 3) shift towards amorphous (higher) wavenumbers while bands related to out of plane bending modes from the aromatic hydrogens $\left(1000-700 \mathrm{~cm}^{-1}\right)$ towards crystalline (lower) wavenumbers. The peak shifts towards higher wavenumbers suggests a decrease in bond length. This may occur due to a change in electronegativity of the neighbouring atom caused by crosslinking after bond scission, or loss of hydrogen or electrons. The broadening of peaks is due to increased intermolecular interactions such as hydrogen bonding. Chain scission and crosslinking may occur simultaneously which leads to a decrease and an increase in crystallinity respectively. Chalmers et al. found a relationship between the degree of crystallinity and the ratio of the absorbance at band around 1306 to that around $1280 \mathrm{~cm}^{-1}$ [28]. Based on this relationship, our results suggest that the degree of crystallinity in descending order: PEEK disc > PEEK wear track $>$ transferred film $>$ sheared film $>$ debris.

Table 3: Observed changes in spectra of PEEK transferred materials on steel as compared to the spectrum of pristine PEEK and possible mechanisms of such changes

\begin{tabular}{|c|c|c|c|c|}
\hline $\begin{array}{c}\text { Wavenumber } \\
\left(\mathrm{cm}^{-1}\right)\end{array}$ & $\begin{array}{c}\text { Peak } \\
\text { assignment }\end{array}$ & Observation & Inference & $\begin{array}{l}\text { Driving } \\
\text { factors }\end{array}$ \\
\hline $3000-3500$ & $\begin{array}{l}\text { Polymeric } \\
\text { hydrogen-bonded } \\
\text { OH stretching }\end{array}$ & $\begin{array}{l}\text { New Phenolics or } \\
\text { Alcohols bands }\end{array}$ & Oxidation & $\begin{array}{l}\text { UV } \\
\text { irradiation }\end{array}$ \\
\hline $2700-2800$ & $\mathrm{H}-\mathrm{C}=\mathrm{O}$ & $\begin{array}{l}\text { New } \\
\text { bands }\end{array}$ & Oxidation & $\begin{array}{l}\text { UV } \\
\text { irradiation }\end{array}$ \\
\hline $\begin{array}{l}1730- \\
1740,1780\end{array}$ & $\mathrm{O}-\mathrm{C}=\mathrm{O}$ & $\begin{array}{l}\text { Shoulder of Ester } \\
\text { bands }\end{array}$ & Oxidation & $\begin{array}{l}\text { Thermal } \\
\text { treatment } \\
\text { Ion } \\
\text { irradiation }\end{array}$ \\
\hline
\end{tabular}




\begin{tabular}{|c|c|c|c|c|}
\hline $1200-1100$ & $\begin{array}{l}\mathrm{C}-\mathrm{O}-\mathrm{C} \quad \text { (bending } \\
\text { and stretching) }\end{array}$ & $\begin{array}{l}\text { Shifting, } \\
\text { broadening and } \\
\text { splitting of Ether } \\
\text { bands }\end{array}$ & $\begin{array}{l}\text { Crosslinking \& } \\
\text { Chain scission }\end{array}$ & $\begin{array}{l}\text { Thermal } \\
\text { treatment } \\
\text { Ion } \\
\text { irradiation }\end{array}$ \\
\hline 1500 & $\begin{array}{l}\mathrm{C}=\mathrm{C} \text { phenyl ring } \\
\text { vibration }\end{array}$ & $\begin{array}{l}\text { Decreased } \\
\text { intensity }\end{array}$ & Oxidation & $\begin{array}{l}\text { UV } \\
\text { irradiation } \\
\text { Thermal } \\
\text { treatment } \\
\text { Ion } \\
\text { irradiation }\end{array}$ \\
\hline $1000-800$ & $\begin{array}{l}\mathrm{C}-\mathrm{H} \text { of phenyl } \\
\text { rings }\end{array}$ & $\begin{array}{l}\text { Decreased } \\
\text { intensity }\end{array}$ & $\begin{array}{c}\text { Reduced } \\
\text { crystallinity }\end{array}$ & $\begin{array}{l}\text { Mechanical } \\
\text { shearing } \\
\text { Thermal } \\
\text { treatment } \\
\text { Ion } \\
\text { irradiation }\end{array}$ \\
\hline
\end{tabular}

Peaks not usually associated with PEEK are also found in spectra of PEEK transferred materials. A peak around $1790 \mathrm{~cm}^{-1}$ (between zone 4 and 5, Figure 7), which is linked to the formation of aryl and $\alpha, \beta$-unsaturated acid peroxides [29], is observed. Bands of overtones due to the aromatic ring vibrations appears in the region $2000-1800 \mathrm{~cm}^{-1}$ (zone 5 , Figure 7 ). They are indicative of the distribution, and positions of substituents in the aromatic rings [29]. The peaks 1884 and $1922 \mathrm{~cm}^{-1}$ arise from the 1,4 (para) di-substituted benzene ring. Peaks at $2072 \mathrm{~cm}^{-1}$ and at $2028 \mathrm{~cm}^{-1}$ are characteristics of symmetric and asymmetric stretching of C$\mathrm{O}$ bond respectively [30] which may suggest the formation of gym dicarbonyl species (CO-Ph$\mathrm{CO}$ or CO-Metal-CO). Their intensities vary as PEEK debris $>$ sheared film $>$ transferred film.

Peak at $1635 \mathrm{~cm}^{-1}$, which is linked to hydrogen bonded carbonyl (v(CO.....H-O-H)) or v(CO)ahydroxyl diaryl ketone group and is usually associated with PEEK [31], is not observed in spectra of PEEK transferred materials. This suggests that the carbonyl bonds are not hydrogen bonded. Peaks at 1750, 1745, $1715 \mathrm{~cm}^{-1}$, which are linked to production of new carbonyl species such as esters and fluorenone type structures, are also absent. Therefore, ester and fluorenone type structures are unlikely to have formed in our PEEK-steel rubbing contacts.

Very weak peaks characteristic of aldehydes $(\mathrm{O}=\mathrm{C}-\mathrm{H})$ stretch are observed in the region 2830$2695 \mathrm{~cm}^{-1}$ (zone 6, Figure 7) for the debris and sheared films (see also Figure S3-1 and Table $\mathrm{S}_{3}-1$ ). The peaks between 3000 and $3100 \mathrm{~cm}^{-1}$ (zone 7, Figure 7) such as 3100, 3088, 3044 and $3008 \mathrm{~cm}^{-1}$ are generally related to the stretching vibrations of $=\mathrm{C}-\mathrm{H}$ stretch from aromatic rings. In particular, the $3044 \mathrm{~cm}^{-1}$ absorption band has been assigned to phenyl ring stretching vibration $v\left(\mathrm{C}_{3}-\mathrm{H}\right)$ and $v\left(\mathrm{C}_{5}-\mathrm{H}\right)$. The intensities of these bands vary in the order sheared film $>$ debris $>$ transfer film $>$ PEEK wear track. 
A broad peak with a maximum around $3330 \mathrm{~cm}^{-1}$ and another band around $3270 \mathrm{~cm}^{-1}$ are observed only in the case of the central transfer film and is linked to the hydroxyl absorption (see Figure $\mathrm{S}_{3}-1$ for detailed spectra). The former lies in the range of polymeric hydrogenbonded $\mathrm{OH}$ stretch while the latter is in the range linked to $\mathrm{OH}$ vibration of acid groups [32].

Our results suggest that rubbing promotes chain scission, opening of the aromatic rings, substitution, crosslinking, along with loss of crystallinity, and coplanarity of the rings. Degradation associated with ring opening, crosslinking and substitution is possible only by radical generation which requires dehydrogenation/hydrogen abstraction. Random chain scission at the ether and ketone linkages must occur first to generate stable radicals intermediates [33,34]. Dehydrogenation has been shown to be affected by thermal treatment [35,36], UV treatment [32,37,38], ion irradiation [31]. The relative decrease in the peak intensity at $1226 \mathrm{~cm}^{-1}$ and the relative intensity increase of peaks at 1653,1599 , and $1493 \mathrm{~cm}^{-1}$ observed in this work (peaks between zones 3 and 4 , Figure 6) have been attributed to a change in chemical bonding due to plasma treatment [9] and melting [35,39]. The band $3044 \mathrm{~cm}^{-1}$ is known to increase with an increase in ion irradiation [40] and decrease with UV exposure $[38,41,42]$. The roles of ion/ UV irradiation and temperature in the chemistry of the transferred materials are discussed in section 3.3. Note that severe chain scission and mastication of polymer chains can also lead to very thin carbonaceous films bound to the counterface by strong force of adhesion.

\subsubsection{Analysis based on Raman spectra}

The FTIR spectra suggest that thin films present in the steel wear scar underwent the most severe degradation with complete oxidation of ketone and ether moieties, leading to the formation of amorphous carbonaceous film. Rebelo de Figueiredo et al. observed similar PEEK degradation after rubbing using Raman spectroscopy (with $532 \mathrm{~nm}$ excitation). D and $\mathrm{G}$ bands of amorphous carbon around 1350 and $1580 \mathrm{~cm}^{-1}$ were found on the transfer films on steel surfaces [43] although the spectrum of PEEK wear track did not contain peaks related to PEEK degradation. Instead peaks related to iron oxides hematite $\left(\mathrm{Fe}_{2} \mathrm{O}_{3}\right)$ and magnetite $\left(\mathrm{Fe}_{3} \mathrm{O}_{4}\right)$ were present. This is inconsistent with our FTIR results. It is unclear if the authors have taken into account the background fluorescence of PEEK, which may hinder PEEK degradation detection. To reduce PEEK background fluorescence, Raman spectroscopy using a $785 \mathrm{~nm}$ laser for excitation was employed in this study (see Figure 8, see also Figure S4-1 for Raman spectra obtained with $532 \mathrm{~nm}$ excitation). Conventionally the relative intensities of spectral modes is obtained by keeping the intensity of the most intense band, the $1146 \mathrm{~cm}^{-1}$ peak in this case, constant. However, this peak has been reported to change [44,45]. Consequently, the second most intense band at $1595 \mathrm{~cm}^{-1}$ is fixed, as shown in Figure 8. 


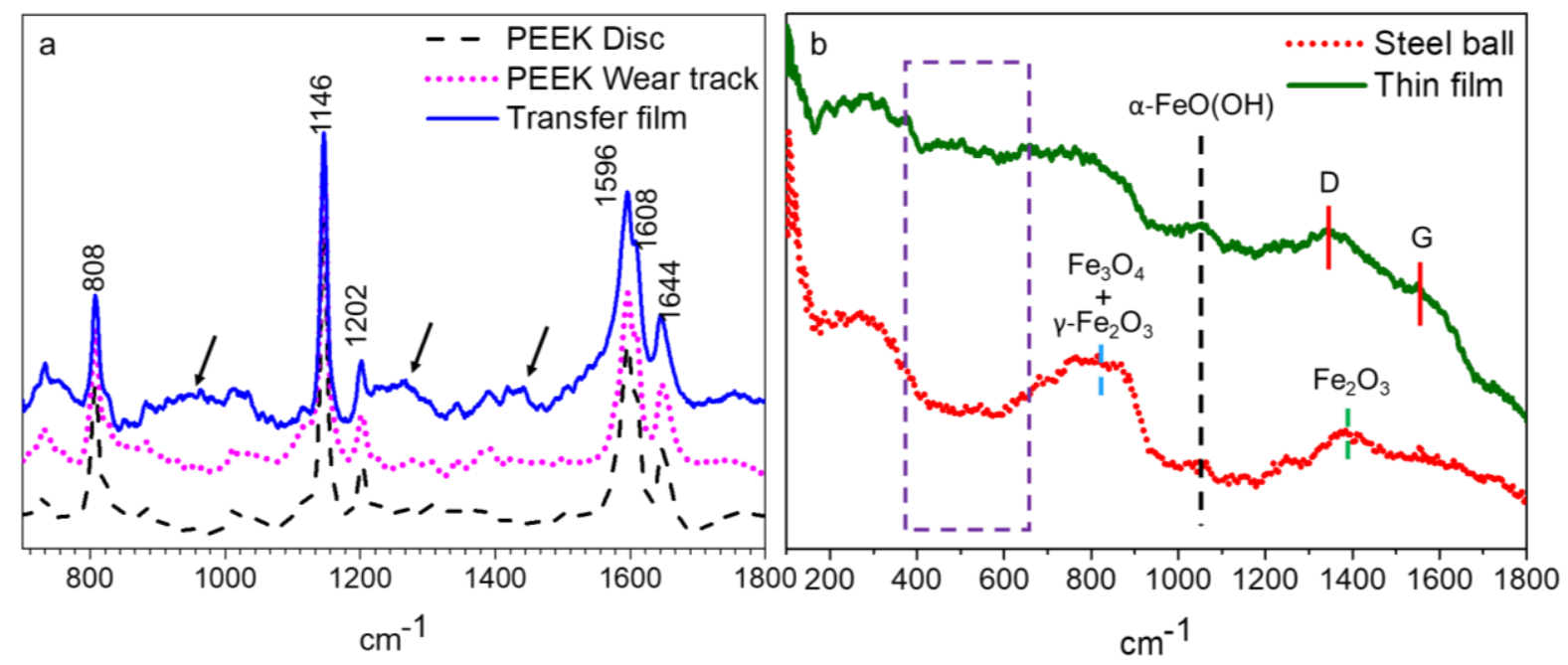

Figure 8: Raman spectra (with $785 \mathrm{~nm}$ excitation) of clean steel ball, pristine PEEK disc, PEEK wear track, and transfer film and thin film on steel wear scar.

Under $785 \mathrm{~nm}$ excitation, Raman peaks of PEEK are observed at 808, 1146, 1202, 1596, 1608 and $1644 \mathrm{~cm}^{-1}$ (see Figure 8a) [45,46]. The peak for the $\mathrm{C}=\mathrm{O}$ stretching mode $\left(1644 \mathrm{~cm}^{-1}\right)$ have the same wavenumber for the pristine PEEK disc, the PEEK wear track and the transfer film. This suggests that they have similar crystallinity. This contradicts our observations with FTIR studies and may be due to the relatively low signal-to-noise ratio in Raman. A broader phenyl ring stretching vibration band $\left(1595 \mathrm{~cm}^{-1}\right)$ is observed in the Raman spectrum of the transfer film. New broad bands also appear around $1400 \mathrm{~cm}^{-1}$, between $1200-1300 \mathrm{~cm}^{-1}$, and between 900 and $1000 \mathrm{~cm}^{-1}$ (see arrows, Figure 8a). These new bands may arise from the formation of other aromatic rings [47] or ring opening reactions by oxidative attack on phenyl moieties [41].

The relative peak heights of stretching mode of ether (C-O-C) linkage (1201 and $1146 \mathrm{~cm}^{-1}$ ), stretching mode of $\mathrm{C}-\mathrm{H}\left(808 \mathrm{~cm}^{-1}\right)$ and $\mathrm{C}=\mathrm{O}$ stretching mode $\left(1644 \mathrm{~cm}^{-1}\right)$ to $\mathrm{C}-\mathrm{C}$ stretching (1596 $\left.\mathrm{cm}^{-1}\right)$, denoted as $\mathrm{I}_{1201 / 1596}, \mathrm{I}_{1146 / 1596}, \mathrm{I}_{808 / 1596}$ and $\mathrm{I}_{1644 / 1596}$ respectively, obtained from various spectra are shown in Table 4. $\mathrm{I}_{1201 / 1596}, \mathrm{I}_{1146 / 1596}, \mathrm{I}_{808 / 1596}$ are lower, while I 1644/1596 is higher for the transfer film than those of the pristine PEEK. Previous studies have shown that the relative intensity of $1146 \mathrm{~cm}^{-1}$ peak (C-O-C stretch mode) in PEEK increases with temperature until about $100^{\circ} \mathrm{C}$ and decreases until about $120^{\circ} \mathrm{C}$ and then increases again until melting [45,48]. The opposite trend is observed in $\mathrm{C}=\mathrm{O}$ stretch in the same temperature range. These changes were linked to the thermally induced movement of the ether linkages of PEEK below $T_{g}[45,48]$. The results here thus suggest that the temperature experienced by PEEK transferred materials are likely to be below $\mathrm{T}_{\mathrm{g}}$, and the highest temperature that the transfer film is subjected to is between 100 and $120^{\circ} \mathrm{C}$. 
Table 4: Relative intensities of the Raman modes of PEEK

\begin{tabular}{|c|c|c|c|c|}
\hline \multirow[b]{3}{*}{ Wavenumber } & \multirow{3}{*}{$\begin{array}{c}\text { Pristine } \\
\text { PEEK Disc }\end{array}$} & \multicolumn{2}{|c|}{ Sheared Materials } & \multirow{3}{*}{$\begin{array}{c}\text { Change relative to } \\
\text { Pristine PEEK }\end{array}$} \\
\hline & & PEEK Wear & & \\
\hline & & track & Transfer film & \\
\hline 1596.41 ( C-C ) fixed & 0.549 & 0.535 & 0.721 & \\
\hline $1644.55(\mathrm{C}=\mathrm{O})$ & 0.235 & 0.258 & 0.379 & \\
\hline $\mathrm{I}_{1644 / 1596}$ & 0.427 & 0.482 & 0.525 & positive \\
\hline $1201.76(\mathrm{C}-\mathrm{O}-\mathrm{C})_{\mathrm{assym}}$ & 0.212 & 0.190 & 0.241 & \\
\hline$I_{1201 / 1596}$ & 0.385 & 0.356 & 0.335 & negative \\
\hline $1146.83(\mathrm{C}-\mathrm{O}-\mathrm{C})_{\mathrm{sym}}$ & 0.994 & 1 & 0.975 & \\
\hline$I_{1146 / 1596}$ & 1.808 & 1.866 & 1.352 & negative \\
\hline $808.35(\mathrm{C}-\mathrm{H})$ & 0.471 & 0.468 & 0.482 & \\
\hline $\mathrm{I}_{808 / 1596}$ & 0.857 & 0.874 & 0.669 & negative \\
\hline
\end{tabular}

The Raman spectrum of a clean steel ball shows a broad asymmetric band between 600 and $900 \mathrm{~cm}^{-1}$ (Figure $7 \mathrm{~b}$ ) as the $\mathrm{A}_{1 \mathrm{~g}}$ mode of magnetite $\left(\mathrm{Fe}_{3} \mathrm{O}_{4}\right)$ at $669 \mathrm{~cm}^{-1}$ superimposes with the broad maghemite band $\left(\gamma-\mathrm{Fe}_{2} \mathrm{O}_{3}\right)$ at $720 \mathrm{~cm}^{-1}$ [49]. The peak at $1380 \mathrm{~cm}^{-1}$ is attributed to hematite $\left(\alpha-\mathrm{Fe}_{2} \mathrm{O}_{3}\right)$. A weak peak at $1060 \mathrm{~cm}^{-1}$ corresponds to $\alpha-\mathrm{FeOOH}$ is also observed. Apart from these oxide related peaks, the spectrum of the thin film on the steel ball wear scar also shows bands around 1350 and $1580 \mathrm{~cm}^{-1}$. They are linked to the D and $\mathrm{G}$ bands of amorphous carbon, although the former can also be assigned to $\gamma-\mathrm{Fe}_{2} \mathrm{O}_{3}$ [50]. A new broad band between 400 and $600 \mathrm{~cm}^{-1}$ (dotted rectangle, Figure $7 \mathrm{~b}$ ) is observed on the spectrum of the thin film. This can be linked to iron oxides such as $\delta$-FeOOH, $\mathrm{Fe}_{3} \mathrm{O}_{4}$ and $\mathrm{FeO}$ [5O]. It should be noted that no signature of PEEK is found. This supports the FTIR results that thin films on steel wear scar are highly degraded.

\subsection{Factors influencing PEEK degradation}

\subsubsection{Frictional heating}

Bulk temperatures of the ball and the disc were measured during rubbing. The metal ball (stars, Figure 9) always has higher temperature than the PEEK disc (squares, Figure 9). This is because in our experiments the ball is stationary and is thermally more conductive than the PEEK disc. The bulk temperatures of steel (stars, Figure 9) and sapphire balls (S1triangles, Figure 9) are about 100 and $70^{\circ} \mathrm{C}$ respectively, and bulk temperatures of their corresponding PEEK disc are about 40 and $30^{\circ} \mathrm{C}$ at the end of the tests. 


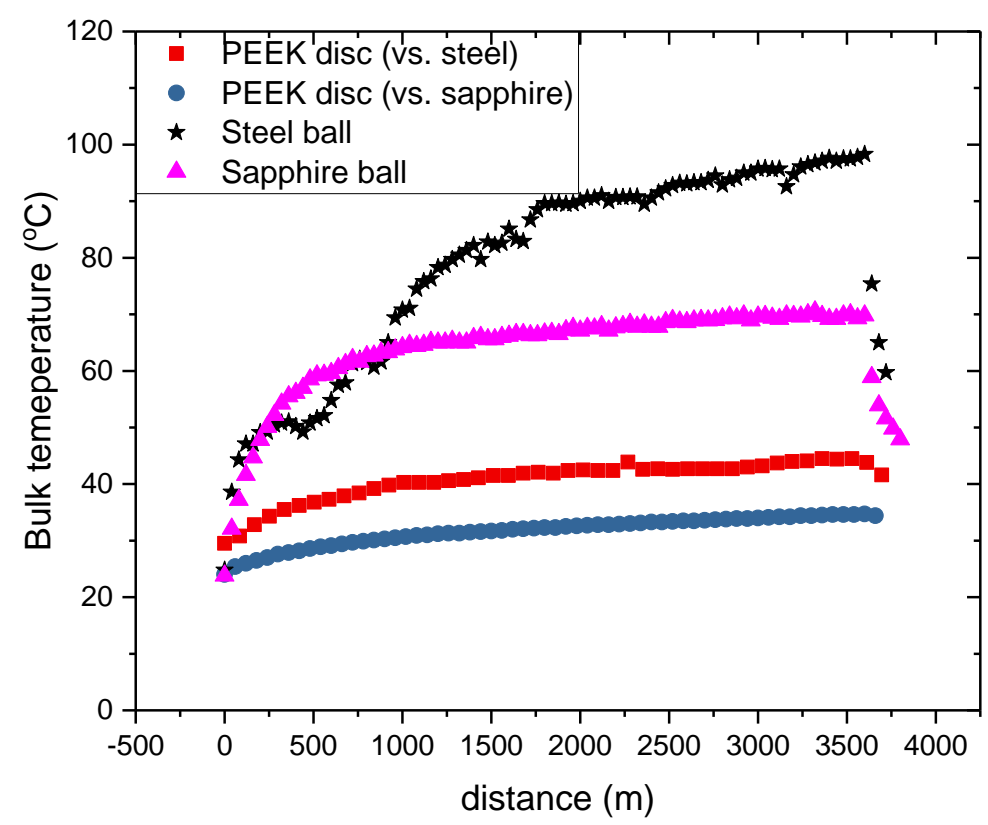

Figure 9: Bulk temperature of balls and discs during rubbing (one data point is displayed for every 50 points collected for clarity)

During rubbing, a sharp temperature rise, called the flash temperature, occurs at the rubbing interface due to frictional heating [51,52]. For the PEEK-sapphire contact, the contact temperature was obtained by IR thermography. Note that the contact temperature depends on pressure, which changes with positions in the contact. Local temperature can be raised at a local asperity level. This is however a transient phenomenon, lasts only as long as $10 \mu \mathrm{s}$, and is difficult to measure. The local temperature can also increase as debris accumulate around the contact and debris entrain into the contact, causing the local pressure to change. This is confirmed by IR thermographic snapshots for a PEEK-sapphire contact (Figure 10, see also video SI 3). Part of the contact is above $100{ }^{\circ} \mathrm{C}$ almost as soon as rubbing starts (see Figure $10 b$, measured temperature can be found in Figure $\mathrm{S}_{5}-1$ ). The temperature at the inlet, where the ploughed material accumulates and is sheared (Figure 10c-h), increases. Some of the sheared materials are drawn into the contact where they are shredded. The formation and breaking of sheared films is a chaotic process. Some are swiped around the contact, while other are eventually entrained into the contact, forming local hot spots. The high local temperature the sheared films are subjected to may prompt their degradation. The longer they remain in the contact the more heat, and hence more degradation they experience. For the entrained debris, the high temperature makes them more susceptible to shear deformation and degradation. 

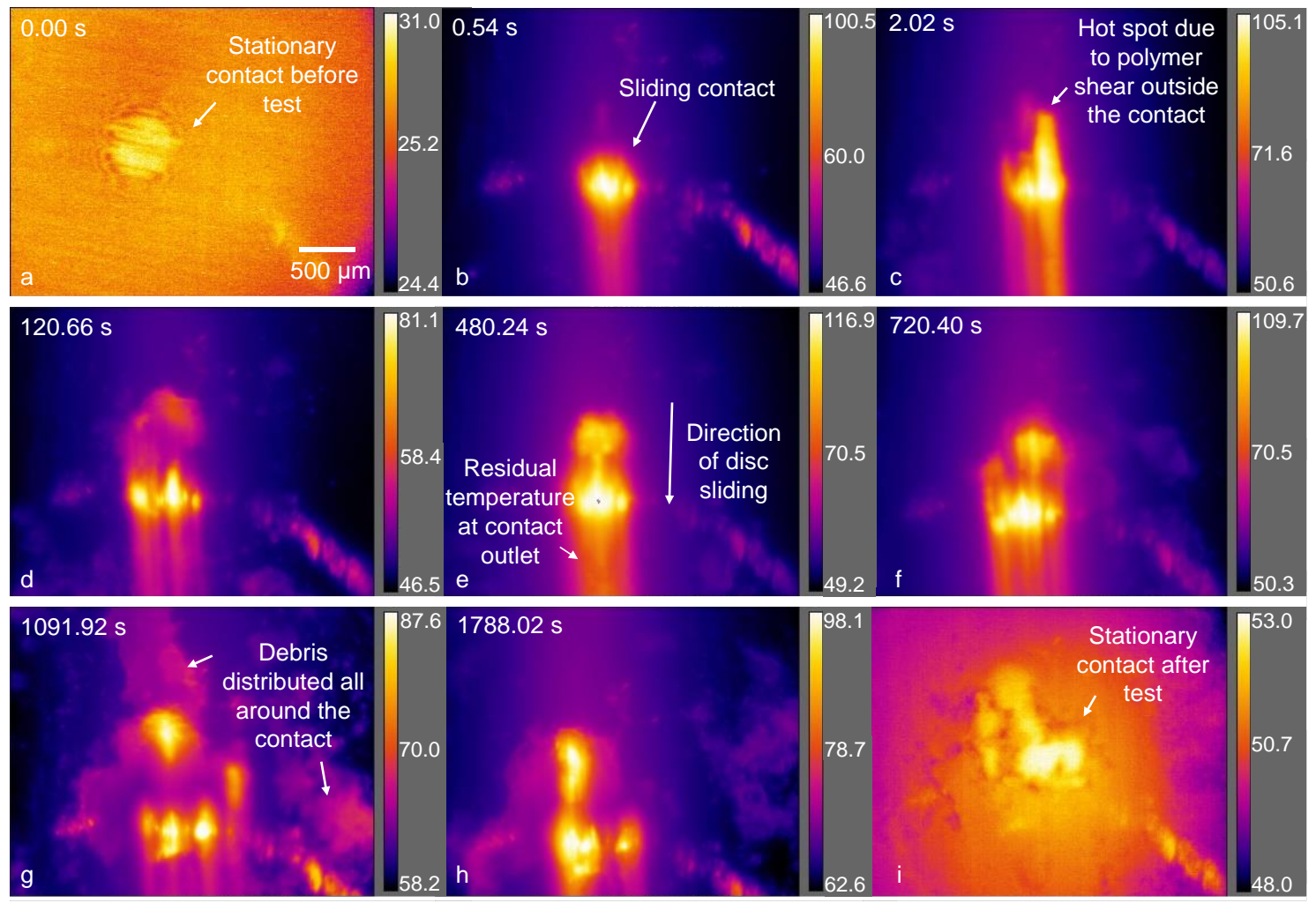

Figure 10: Snapshots of in-situ temperature measurement using IR imaging. The colour bars are temperature scales which change among images.

It is anticipated that similar phenomena applies to the PEEK-steel contact. Since the bulk temperatures of the PEEK-steel contact are higher than those of the PEEK-sapphire contact (see Figure 9), the contact temperature for the former is likely to be higher.

Heating PEEK at $400^{\circ} \mathrm{C}$ in air has been shown to cause decomposition, chain branching, and crosslinking [53]. Zhang et al. estimated interfacial temperatures in the range 300 to $345^{\circ} \mathrm{C}$ at which PEEK plastic flow occurs based on the chemistry PEEK wear debris [39]. It was suggested that thermo-oxidative cross-linking reactions occurred in PEEK which reduced its crystallinity [39]. However, our results support that the contact temperature is only near the $\mathrm{T}_{\mathrm{g}}$ of PEEK. These contact temperatures match the temperature suggested by results in the Raman study (section 3.2.3) and are alone insufficient to cause thermal degradation of PEEK. While our results cannot eliminate the existence of high flash temperature due to the lack of temporal resolutions, they support that factors other than temperature, such as UV/ion irradiation due to triboemission, assisted by mechanical shear, may contribute to the change in chemistry of transferred materials evidenced by FTIR studies.

\subsubsection{Triboemission}

Plasma, consisting of electrons, ions and photons, is known to promote surface modification through processes such as etching, chain scission, cross-linking and chemical 
functionalization [54]. Similarly triboplasma may modify rubbing surfaces by producing high energy active sites which are extremely reactive [55]. Indeed triboelectrification and triboemission (emission of electrons) are known to occur during rubbing and have been linked with polymer chain scission [56]. Note that some features in FTIR spectra of PEEK transferred materials are similar to those of plasma treated PEEK in literature $[9,31,38,57]$. Hence, the effect of triboplasma on the rubbing surfaces and transferred materials must be considered.

\subsubsection{Observations of triboplasma}

The PEEK wear track was positively charged (shown in Figure S6-1). Consequently, an electric field is created between the steel ball and the charged PEEK wear track. When the strength of the electric field surpasses the dielectric strength of the air $(3 \mathrm{kV} / \mathrm{mm}$ for air), electric breakdown of air occurs by a corona discharge process [70]. Plasma streamers are generated as electrons of the neutral steel ball (earthed conductor) are pulled towards the charged wear track. This is observed at the gap between the stationary ball and a rotating PEEK disc, and along the wear track (see Figure 11, also see video SI 4). The spectrum of the emitted plasma resembled the $\mathrm{N}_{2}$ breakdown spectrum as shown in Figure 12.
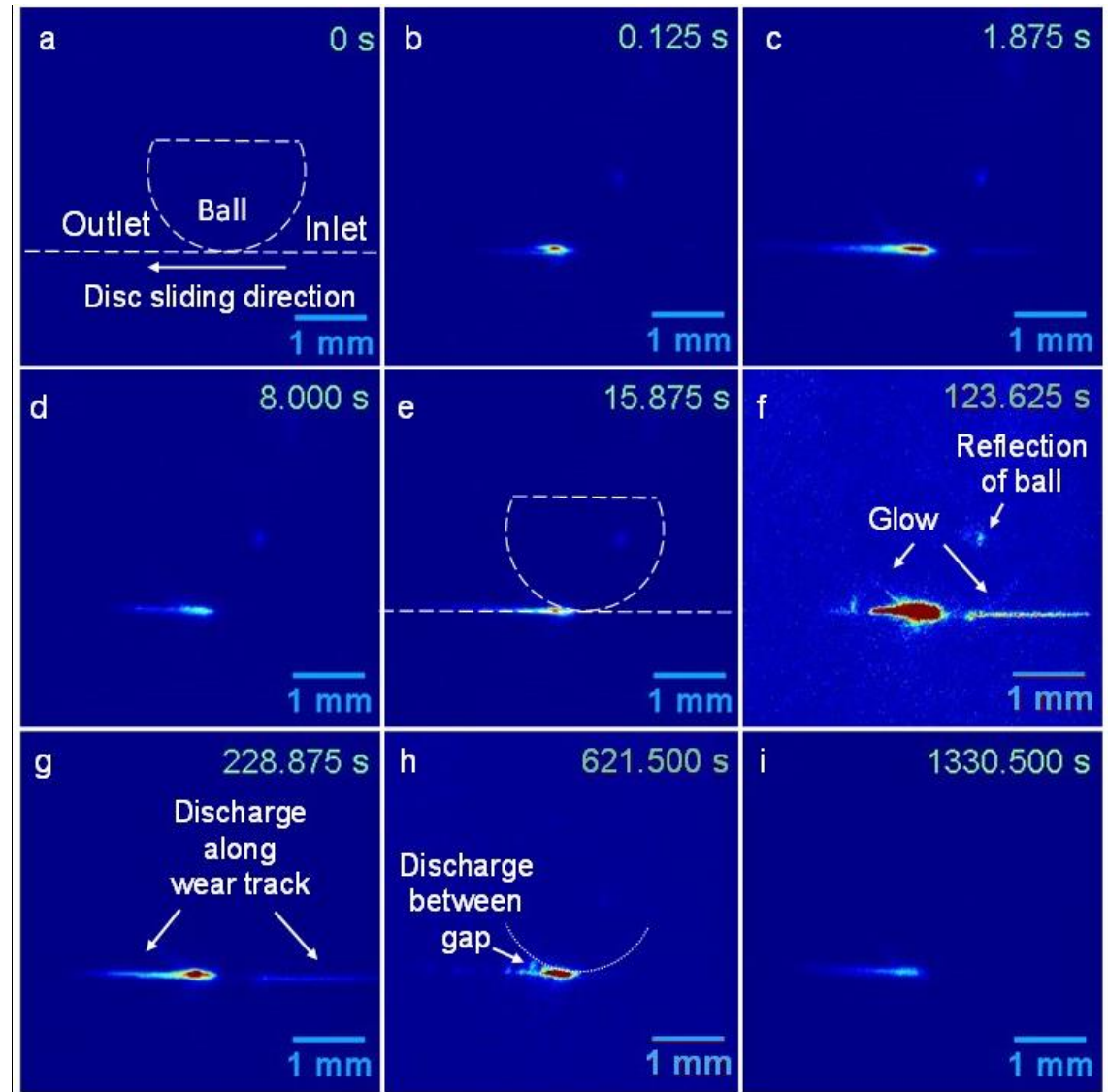

Figure 11: Plasma generated when a steel ball was rubbed against a PEEK disc. Note that the brightness and contrast has been adjusted in (f) and (h) to show the glow along ball edge and localized corona discharge events. 
The intensity of plasma varies with time. Initially, plasma is observed in the gap between the ball and the disc at the outlet. After a while, it is also seen at the inlet (Figure 11f). The variation is linked to the gap geometry and the electric field generated, which change due to the generation of wear debris, materials transfer and the re-entering charged wear track. Occasionally, a glow at the edge of the steel ball is observed as well as a localized corona discharge (Figure 11f and 11h). The overall intensity of the transient plasma luminescence reduces as sliding progresses. A detailed explanation of plasma luminescence from polymer contact can be found in ref [58].

\subsubsection{Potential Links between plasma generations and chemistry of PEEK transferred materials}

Although some of the chemical changes reported in Table 3 have been linked to ion irradiation on PEEK surface $[31,40,59,60]$, PEEK in general has very good resistance to ion irradiation [6o]. Its UV resistance however is weak and it adsorbs UV in the range, $\lambda=300-380 \mathrm{~nm}$ [41]. The damage from UV irradiation is supported by the fracture of transfer films shown in Figure $4 \mathrm{~g}$ and $4 \mathrm{i}[24]$.

Based on the plasma emission spectrum in Figure 12, the energy of the UV photons is in the range $3.2-4.43 \mathrm{eV}$. This is sufficient to break bonds, including $\mathrm{C}-\mathrm{C}(3.48 \mathrm{eV}), \mathrm{C}-\mathrm{H}(4.13 \mathrm{eV})$, $\mathrm{O}-\mathrm{H}(3.66 \mathrm{eV}), \mathrm{C}-\mathrm{O}(3.6 \mathrm{eV})$. The resulting radicals can participate in various reactions. A competition between chain scission and crosslinking in PEEK under UV irradiation may occur $[38,41,42,61]$. This could be a reason for IR spectra of transferred materials to have some peaks (1457-1453, 1415, 1310, 1281, 1226, 1159, 1187, 1115, 1101, 864, 847, 838, 870, 964, 951, 928, $\left.768 \mathrm{~cm}^{-1}\right)$ shifted towards crystalline bands while other peaks $(1647,1593,1500,1493,1485$ and $1410 \mathrm{~cm}^{-1}$ ) towards amorphous bands (see Table S3-1). 


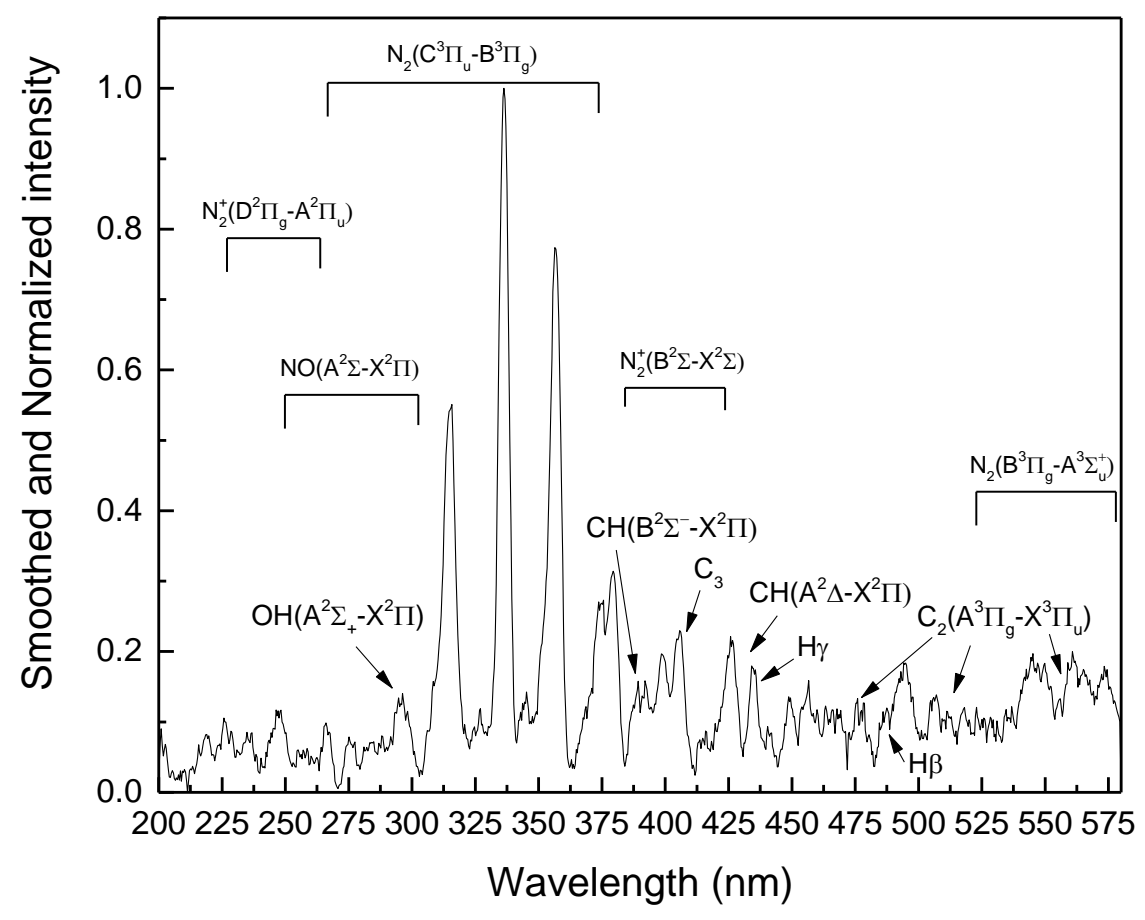

Figure 12: Emission spectrum of the observed triboplasma. Strong emission is observed from the first negative system of the nitrogen molecular ion $(\mathrm{N} 2+(\mathrm{B} 2 \Sigma \mathrm{u}-\mathrm{X} 2 \Sigma \mathrm{g}), 329.3 \mathrm{~nm}-$ $586.5 \mathrm{~nm}$ ) and the second positive system of the nitrogen molecule (N2 ( $\left.\mathrm{C}_{3} \Pi \mathrm{u}-\mathrm{B} 3 \Pi \mathrm{g}\right)$, $281.4 \mathrm{~nm}-497.6 \mathrm{~nm})$. Weak emissions from the first positive system of the nitrogen molecule (N2 (B3Пg-A3Пu), $503.1 \mathrm{~nm}-800 \mathrm{~nm}$ ) (about 100 times weaker) [62-64] and nitric oxide $\gamma$-system (NO (A2 $\Sigma$ - X2П), 250-300.8 nm) [65] are also detected. Non-nitrogen radicals, such as $\mathrm{CH}(\mathrm{A} 2 \Delta-\mathrm{X} 2 \Pi)$ and $\mathrm{C}_{2}(\mathrm{~A} 3 \Pi g-\mathrm{X} 2 \Pi u)$, including bands at 400, 425 and 475 $\mathrm{nm}$, may be generated from polymer bond scission and triboemission of volatile products

[66].

The presence of bands corresponding to $\mathrm{H}^{*}, \mathrm{OH}^{*}, \mathrm{CH}^{*}$ and $\mathrm{C}_{2}{ }^{*}$ in the plasma emission spectrum confirm the formation of radicals $\mathrm{R}^{*}$ in the polymer. These radicals may promote PEEK degradation. For example, $\mathrm{CH}^{*}$ may react with unsaturated carbon-carbon bonds by addition across the pi-bonds of neighbour radicals. The free hydrogen radicals, which can diffuse very easily through the polymer matrix, may cause hydrogen abstraction of polymer chains, or recombine with a polymer radical (crosslinking) or with hydrogen radicals. $\mathrm{H}^{*}$ may also induce oxidation and cleavage of the rings of intermediate species to form chain aliphatic acids in the presence of reactive oxygen species (e.g. $\mathrm{R}-\mathrm{OO}^{*}$ and $\mathrm{OH}^{*}$ ). $\mathrm{R}-\mathrm{OO}^{*}$ are known to form when alkenyl or phenacyl radicals react with molecular oxygen, which is available in PEEK [67]. Peroxy-radicals can form at temperatures $<100^{\circ} \mathrm{C}$ in presence of UV light from the plasma [68,69].

The presence of a transition metal such as iron $\left(\mathrm{Fe}^{2+}\right)$ at the interface may promote the reduction of the radicals and increased chelation. Radicals are known to react with metal ions via the hydrogenation of the organic radical [70-73]. Moreover, metal carbonates (ester) may be generated by the linkage of $\mathrm{CO}^{*}$ radicals with the coordinatively unsaturated Lewis acid- 
base pair sites $\left(\mathrm{M}^{\mathrm{n}+}-\mathrm{O}^{2-}\right)$ on the counterface. These reactions may be responsible for the strong adhesion observed with the transfer materials on steel surfaces.

Note that the scission of polymer chains and formation of primary radicals may occur due to mechanical shear [7,74-77]. The primary (end) radicals are very reactive and react readily with adjacent polymer molecules to form secondary (internal) radicals, producing low molecular weight fragments through auto oxidation [69]. For PEEK, Zhang et al. have suggested that friction and wear can lead to the diphenyl ether segment undergoing chain scission, and the formation of oxidative crosslinks by combining with adjacent radicals [39]. Hence the existence of both triboplasma and mechanical shear are likely to exacerbate PEEK degradation.

\section{Conclusions}

When PEEK is rubbed against sapphire and steel, it is transferred to the counterfaces under our test conditions. The formation of PEEK transfer layers was examined by in-situ monitoring of the wear process, contact temperature, and triboplasma generation. As rubbing starts, the PEEK surface is initially ploughed by the asperities of the steel ball. Some of these materials are entrained and sheared in the contact. Debris form, as well as materials transfer occurs.

The chemistry of PEEK transferred materials on wear scars differ from that of pristine PEEK. The thin film, which are formed between the thicker transfer films and the counterface, is mainly amorphous carbonaceous materials. FTIR results of other PEEK transferred materials suggest scission of PEEK chains occurs at various positions in the ether and ketone groups. In addition, opening of the aromatic rings, substitution, crosslinking, along with loss of crystallinity, and co-planarity of the rings are observed. Carbonate and carboxylic acid may form and react with steel or sapphire surface through an acid-base reaction, forming the thin and robust transfer films.

In-situ IR thermography shows that the nominal contact temperature is below PEEK $\mathrm{T}_{\mathrm{g}}$ even though local temperature is raised by the entrainment of debris. Results from Raman studies support that the contact temperature $\left(100-120^{\circ} \mathrm{C}\right)$ is below the $\mathrm{T}_{\mathrm{g}}$ of PEEK. Hence contact temperature alone may not be sufficient to generate the PEEK degradations observed. The presence of brittle cracks on the thin film on the steel wear scar also suggests that the deformation temperature may be relatively low and the film may have exposed to UV irradiation. 
The shear experienced by the rubbing surfaces leads to their triboelectrification. As a result, triboplasma is generated during rubbing. This triboplasma has sufficient energy, which together with the mechanical shear, can cause chain scission and generate radicals. This promotes transfer film formation and leads to crosslinking and degradation of PEEK. Our results show that mechanical shear, as well as frictional heating and triboplasma all contribute to the formation and properties of the PEEK transferred materials on the rubbing counterface (Figure 13). Keeping the possibility of UV plasma generation in mind, the design of future polymer and polymer composites should take the possibility of surface charging and the potential effect it may have on transfer film formation and degradation into considerations.

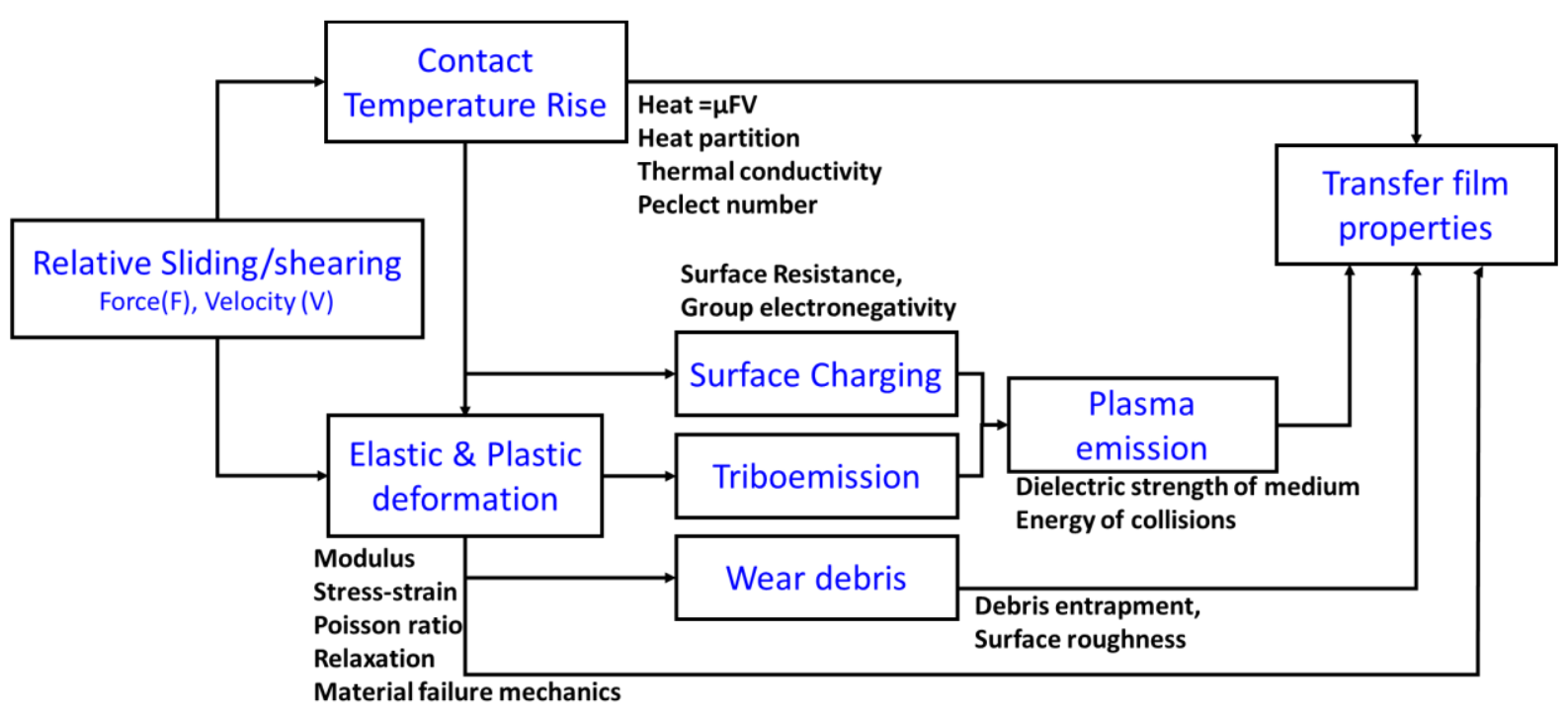

Figure 13: Summary of factors influencing properties of polymeric transfer film on rubbing counterface.

Acknowledgement: The authors gratefully acknowledge Dr Philippa Cann for her help in the FTIR studies and Dr Tom Reddyhoff for his advice on IR thermography measurements and observations of triboplasma. Test samples were kindly donated by Victrex and Hoerbiger..

References

[1] Lu ZP, Friedrich K. On sliding friction and wear of PEEK and its composites. Wear 1995;181-183:624-31. doi:10.1016/0043-1648(95)90178-7.

[2] Bijwe J, Kadiyala AK, Kumar K, Puhan D, Parida T, Trivedi P. Development of high performance poly (ether-ketone) composites based on novel processing technique. Mater Des 2015;73:50-9. doi:10.1016/j.matdes.2015.02.007.

[3] Freidrich K. Wear of Reinforced Polymers by Abrasive Counterparts. vol. 1. 1986. doi:10.1016/B978-0-444-42524-9.50012-0.

[4] Briscoe BJ, Lin Heng Yao, Stolarski TA. The friction and wear of poly(tetrafluoroethylene)-poly (etheretherketone) composites: An initial appraisal of the optimum composition. Wear 1986;108:357-74. doi:10.1016/00431648(86)90013-X. 
[5] Puhan D, Bijwe J, Parida T, Trivedi P. Investigations on performance properties of nano-micro composites based on polyetherketone, short carbon fibers and hexa-boron nitride. Sci Adv Mater 2015;7. doi:10.1166/sam.2015.2142.

[6] Bahadur S. The development of transfer layers and their role in polymer tribology. Wear 2000;245:92-9. doi:10.1016/So043-1648(00)00469-5.

[7] Jintang G. Tribochemical effects in formation of polymer transfer film. Wear 2000;245:100-6. doi:10.1016/So043-1648(00)00470-1.

[8] Laux KA, Schwartz CJ. Effects of contact pressure, molecular weight, and supplier on the wear behavior and transfer film of polyetheretherketone (PEEK). Wear 2013;297:919-25. doi:10.1016/j.wear.2012.11.013.

[9] Zhang R, Häger A., Friedrich K, Song Q, Dong Q. Study on tribological behaviour of plasma-treated PEEK and its composites. Wear 1995;181-183:613-23. doi:10.1016/0043-1648(95)90177-9.

[10] Zhang G, Yu H, Zhang C, Liao H, Coddet C. Temperature dependence of the tribological mechanisms of amorphous PEEK (polyetheretherketone) under dry sliding conditions. Acta Mater 2008;56:2182-90. doi:10.1016/J.ACTAMAT.2008.01.018.

[11] Nakayama K, Mirza SM. Verification of the Decomposition of Perfluoropolyether Fluid Due to Tribomicroplasma. Tribol Trans 2006;49:17-25. doi:10.1080/05698190500414524.

[12] Matta C, Eryilmaz OL, De Barros Bouchet MI, Erdemir A, Martin JM, Nakayama K. On the possible role of triboplasma in friction and wear of diamond-like carbon films in hydrogen-containing environments. J Phys D Appl Phys 2009;42:075307. doi:10.1088/0022-3727/42/7/075307.

[13] VICTREX @ HIGH PERFORMANCE PAEK POLYMERS (CVictrex plc Revision VICTREX @ PEEK 450CA20 2014:1-2. https://www.victrex.com/ /media/datasheets/victrex_tds_650g.pdf (accessed May 14, 2018).

[14] Properties of Synthetic Sapphire n.d. https://www.swissjewel.com/materials/sapphire/ (accessed June 10, 2018).

[15] Reddyhoff T, Schmidt A, Spikes H. Thermal Conductivity and Flash Temperature. Tribol Lett 2019;67:22. doi:10.1007/s11249-018-1133-8.

[16] Singh S V., Kusano Y, Morgen P, Michelsen PK. Surface charging, discharging and chemical modification at a sliding contact. J Appl Phys 2012;111:83501. doi:10.1063/1.3698311.

[17] Vollmer M, Möllmann K-P, Wiley InterScience (Online service). Infrared thermal imaging : fundamentals, research and applications. Wiley-VCH; 2010.

[18] Blok H. Theoretical study of temperature rise at surfaces of actual contact under oiliness lubricating conditions. Proc. Gen. Discuss. Lubr. Lubr. Vol. 2, 1937, p. $222-$ 35 .

[19] Hirschen C, Gülhan A. Infrared Thermography and Pitot Pressure Measurements of a Scramjet Nozzle Flowfield. J Propuls Power 2009;25:1108-20. doi:10.2514/1.41787.

[20] Wittenberg AW. Total Hemispherical Emissivity of Sapphire. J Am Ceram Soc 1965;55:432-5. doi:10.1364/JOSA.55.000432.

[21] Rowe KG, Bennett AI, Krick BA, Gregory Sawyer W. In situ thermal measurements of 
sliding contacts. Tribol Int 2013;62:208-14. doi:10.1016/J.TRIBOINT.2013.02.028.

[22] Zum Gahr K-H. Microstructure and wear of materials. Elsevier; 1987.

[23] Ebewele R. Polymer Science and Technology. New York: CRC Press LLC; 2000. doi:10.1201/9781420057805.

[24] Nikafshar S, Zabihi O, Ahmadi M, Mirmohseni A, Taseidifar M, Naebe M. The Effects of UV Light on the Chemical and Mechanical Properties of a Transparent EpoxyDiamine System in the Presence of an Organic UV Absorber. Mater (Basel, Switzerland) 2017;10. doi:10.3390/ma10020180.

[25] Jiang H, Browning R, Sue HJ. Understanding of scratch-induced damage mechanisms in polymers. Polymer (Guildf) 2009;50:4056-65. doi:10.1016/j.polymer.2009.06.061.

[26] Zhang S., Li JC. Slip process of stick-slip motion in the scratching of a polymer. Mater Sci Eng A 2003;344:182-9. doi:10.1016/So921-5093(02)00409-4.

[27] Pooley CM, Tabor D. Friction and Molecular Structure: The Behaviour of Some Thermoplastics. Proc R Soc A Math Phys Eng Sci 1972;329:251-74. doi:10.1098/rspa.1972.0112.

[28] Chalmers JM, Gasldn WF, Mackenzie MW. Crystallinity in Poly(AryI-Ether-Ketone) Plaques Studied by Multiple Internal Reflection Spectroscopy. Polym Bull 1984;11:433-5.

[29] Socrates G. Infrared and Raman characteristic group frequencies. John Wiley \& Sons; 2004. doi:10.1002/jrs.1238.

[30] El-Bahy ZM. Adsorption of CO and NO on Ceria-and Pt-Supported TiO 2 : In Situ FTIR Study. Mod Res Catal 2013;2:136-47. doi:10.4236/mrc.2013.24019.

[31] Al Lafi AG. FTIR spectroscopic analysis of ion irradiated poly (ether ether ketone). Polym Degrad Stab 2014;105:122-33. doi:10.1016/j.polymdegradstab.2014.04.005.

[32] Lin-Vien D, Colthup N, Fateley W, Grasselli J. The handbook of infrared and Raman characteristic frequencies of organic molecules. 1991.

[33] Perng L., Tsai C., Ling Y. Mechanism and kinetic modelling of PEEK pyrolysis by TG/MS. Polymer (Guildf) 1999;40:7321-9. doi:10.1016/Soo32-3861(99)oooo6-3.

[34] Patel P, Hull TR, Mccabe RW, Flath D, Grasmeder J, Percy M. Mechanism of thermal decomposition of poly(ether ether ketone) (PEEK) from a review of decomposition studies. Polym Degrad Stab 2010;95:709-18. doi:10.1016/j.polymdegradstab.2010.01.024.

[35] Nguyen HX, Ishida H. Molecular analysis of the melting behaviour of poly(aryl-etherether-ketone). Polymer (Guildf) 1986;27:1400-5. doi:10.1016/0032-3861(86)900418.

[36] Nguyen HX, Ishida H. Molecular analysis of the crystallization behavior of poly(arylether-ether-ketone). J Polym Sci Part B Polym Phys 1986;24:1079-91. doi:10.1002/polb.1986.090240510.

[37] Munro HS, Clark DT, Recca A. Surface photo-oxidation of phenoxy resin and polyetheretherketone. Polym Degrad Stab 1987;19:353-63. doi:10.1016/01413910(87)90036-X.

[38] Nakamura H, Nakamura T, Noguchi T, Imagawa K. Photodegradation of PEEK sheets under tensile stress. Polym Degrad Stab 2006;91:740-6.

doi:10.1016/J.POLYMDEGRADSTAB.2005.06.003. 
[39] Zhang MQ, Lu ZP, Friedrich K. Thermal analysis of the wear debris of polyetheretherketone. Tribol Int 1997;30:103-11. doi:10.1016/0301-679X(96)00028$\mathrm{X}$.

[40] Švorčík V, Prošková K, Rybka V, Vacík J, Hnatowicz V, Kobayashi Y. Changes of PEEK surface chemistry by ion irradiation. Mater Lett 1998;36:128-31. doi:10.1016/So167577X(98)00030-5.

[41] Giancaterina S, Rossi A, Rivaton A, Gardette J. Photochemical evolution of poly(ether ether ketone). Polym Degrad Stab 2000;68:133-44. doi:10.1016/So1413910(99)00181-0.

[42] Shi H, Sinke J, Benedictus R. Surface modification of PEEK by UV irradiation for direct co-curing with carbon fibre reinforced epoxy prepregs. Int J Adhes Adhes 2017;73:51-7. doi:10.1016/J.IJADHADH.2016.07.017.

[43] Rebelo de Figueiredo M, Bergmann C, Ganser C, Teichert C, Kukla C, Mitterer C. Adhesion Tendency of Polymers to Hard Coatings. Int Polym Process 2013;28:41520. doi:10.3139/217.2767.

[44] Cole KC, Casella IG. Fourier transform infra-red spectroscopic study of thermal degradation in poly(ether ether ketone)-carbon composites. Polymer (Guildf) 1993;34:740-5. doi:10.1016/0032-3861(93)90357-G.

[45] Briscoe BJ, Stuart BH, Thomas PS, Williams DR. A comparison of thermal- and solvent-induced relaxation of poly(ether ether ketone) using Fourier transform Raman spectroscopy. Spectrochim Acta Part A Mol Spectrosc 1991;47:1299-303. doi:10.1016/0584-8539(91)80219-9.

[46] Agbenyega JK, Ellis G, Hendra PJ, Maddams WF, Passingham C, Willis HA, et al. Applications of Fourier Transform Raman spectroscopy in the synthetic polymer field. Spectrochim Acta Part A Mol Spectrosc 1990;46:197-216. doi:10.1016/o5848539(90)80090-L.

[47] Larkin P (Peter J. Infrared and raman spectroscopy : principles and spectral interpretation. Elsevier; 2011.

[48] Briscoe BJ, Stuart BH, Sebastian S, Tweedale PJ. The failure of poly (ether ether ketone) in high speed contacts. Wear 1993. doi:10.1016/0043-1648(93)90524-P.

[49] Molchan IS, Thompson GE, Lindsay R, Skeldon P, Likodimos V, Romanos GE, et al. Corrosion behaviour of mild steel in 1-alkyl-3-methylimidazolium tricyanomethanide ionic liquids for CO2 capture applications. RSC Adv 2014;4:5300. doi:10.1039/c3ra45872e.

[50] de Faria DLA, Venâncio Silva S, de Oliveira MT. Raman microspectroscopy of some iron oxides and oxyhydroxides. J Raman Spectrosc 1997;28:873-8. doi:10.1002/(SICI)1097-4555(199711)28:11<873::AID-JRS177>3.0.CO;2-B.

[51] Kok JF, Renno NO. Electrostatics in wind-blown sand. Phys Rev Lett 2008;100:014501. doi:10.1103/PhysRevLett.100.014501.

[52] Blok H. The flash temperature concept. Wear 1963;6:483-94. doi:10.1016/00431648(63)90283-7.

[53] Day M, Sally D, Wiles DM. Thermal degradation of poly(aryl-ether-ether-ketone): Experimental evaluation of crosslinking reactions. J Appl Polym Sci 1990;40:1615-25. doi:10.1002/app.1990.070400917.

[54] Kusano Y. Atmospheric pressure plasma processing for polymer adhesion: A review. J Adhes 2014;90:755-77. doi:10.1080/00218464.2013.804407. 
[55] Gengenbach TR, Griesser HJ. Post-deposition ageing reactions differ markedly between plasma polymers deposited from siloxane and silazane monomers. Polymer (Guildf) 1999;40:5079-94. doi:10.1016/Soo32-3861(98)00727-7.

[56] Lacks DJ, Mohan Sankaran R. Contact electrification of insulating materials. J Phys D Appl Phys 2011;44. doi:10.1088/0022-3727/44/45/453001.

[57] Mylläri V, Ruoko T-P, Järvelä P. The effects of UV irradiation to polyetheretherketone fibers - characterization by different techniques n.d.

[58] Puhan D, Nevshupa R, Wong JSS, Reddyhoff T. Transient aspects of plasma luminescence induced by triboelectrification of polymers. Tribol Int 2019;130:366-77. doi:10.1016/j.triboint.2018.09.026.

[59] Hnatowicz V, Havránek V, Bočan J, Macková A, Vacík J. Modification of poly(ether ether ketone) by ion irradiation n.d. doi:10.1016/j.nimb.2007.11.031.

[6o] Ferain E, Legras R. Modification of PEEK model compounds and PEEK film by energetic heavy ion and ultraviolet irradiations. Nucl Instruments Methods Phys Res Sect B Beam Interact with Mater Atoms 1993;83:163-6. doi:10.1016/0168583X(93)95921-Q.

[61] Mylläri V, Ruoko TP, Järvelä P. The effects of UV irradiation to polyetheretherketone fibres - Characterization by different techniques. Polym Degrad Stab 2014;109:27884. doi:10.1016/j.polymdegradstab.2014.08.003.

[62] Deng XL, Nikiforov AY, Vanraes P, Leys C. Direct current plasma jet at atmospheric pressure operating in nitrogen and air. J Appl Phys 2013;113:023305. doi:10.1063/1.4774328.

[63] Lofthus A, Krupenie PH. The spectrum of molecular nitrogen. J Phys Chem Ref Data 1977;6:113-307. doi:10.1063/1.555546.

[64] Camacho JJ, Poyato JML, Díaz L, Santos M. Optical emission studies of nitrogen plasma generated by IR CO 2 laser pulses. J Phys B At Mol Opt Phys J J Camacho Al J Phys B At Mol Opt Phys J Phys B At Mol Opt Phys 2007;40:4573-4573. doi:10.1088/0953-4075/40/24/003.

[65] Laux CO, Spence TG, Kruger CH, Zare RN. Optical diagnostics of atmospheric pressure air plasmas. Plasma Sources Sci Technol Plasma Sources Sci Technol 2003;12:125-38.

[66] Rusanov A, Nevshupa R, Martin JM, Garrido MÁ, Roman E. Tribochemistry of hydrogenated amorphous carbon through analysis of mechanically stimulated gas emission. Diam Relat Mater 2015;55:32-40. doi:10.1016/j.diamond.2015.02.007.

[67] Schweitzer-Chaput B, Boess E, Klussmann M. Acid-Catalyzed Activation of Peroxyketals: Tunable Radical Initiation at Ambient Temperature and Below. Org Lett 2016;18:4944-7. doi:10.1021/acs.orglett.6bo2419.

[68] Clark BDE. Peroxides and peroxide- forming compounds. Div Chem Heal Saf Am Chem Soc Publ by Elsevier Sci 2001;9098:1-22. doi:10.1016/S1074-9098(01)o02477 .

[69] M. B. Smith JM. Advanced Organic Chemistry: Reactions, Mechanisms, and Structure. 2007.

[70] Khudyakov I V, Kuz 'min VA. Oxidation-reduction Reactions of Free Radicals. Uspekhi Khimii Russ Chem Rev 1978;47144:39-82.

[71] Collinson E, Dainton FS, Smith DR, Trudel GJ, Tazuké S. The oxidation and reduction 
of free radicals by metal ions in aqueous solution. Discuss Faraday Soc 1960;29:188204. doi:10.1039/DF9602900188.

[72] La Mare D, Kochi JK, Rust FF, De La Mare E, Kochi K. Organic Peroxides. vol. 83. Interscience Publishers, Inc; 1961.

[73] Behar D, Samuni A, Fessenden RW. Reactions of iron(II) and titanium(III) with organic radicals. J Phys Chem 1973;77:2055-9. doi:10.1021/j100636ao05.

[74] Radtsig VA, Butyagin PY. The free radicals forming during the mechanical destruction of polyethylene and polypropylene. Polym Sci USSR 1967;9:2883-7. doi:10.1016/0032-3950(67)90153-0.

[75] Balestrin LBS, Duque DD, Silva DS, Galembeck F, Beraldo da Silveira Balestrin L, Del Duque D, et al. Triboelectricity in insulating polymers: evidence for a mechanochemical mechanism 2014;170:369-83. doi:10.1039/c3fdoo118k.

[76] Burgo TAL, Ducati TRD, Francisco KR, Clinckspoor KJ, Galembeck F, Galembeck SE. Triboelectricity: Macroscopic charge patterns formed by self-arraying ions on polymer surfaces. Langmuir 2012;28:7407-16. doi:10.1021/la301228j.

[77] Onodera T, Park M, Souma K, Ozawa N, Kubo M. Transfer-Film Formation Mechanism of Polytetrafluoroethylene: A Computational Chemistry Approach. J Phys Chem C 2013;117:10464-72. doi:10.1021/jp400515j. 